Research Article

\title{
Shaking Table Tests on Sliding Displacements of Loess Slope under Coupling Effect of Rainfall and Earthquake
}

\author{
Xiaojun Yin $\mathbb{D I}^{1,2,3}$ and Lanmin Wang $\mathbb{D}^{4,5}$ \\ ${ }^{1}$ Institute of Engineering Mechanics, China Earthquake Administration, Harbin 150080, China \\ ${ }^{2}$ Key Laboratory of Earthquake Engineering and Engineering Vibration of China Earthquake Administration, \\ Harbin 150080, China \\ ${ }^{3}$ College of Mining Engineering, Heilongjiang University of Science and Technology, Harbin 150022, China \\ ${ }^{4}$ Lanzhou Institute of Seismology, China Earthquake Administration, Lanzhou 730000, China \\ ${ }^{5}$ Key Lab of Loess Earthquake Engineering, China Earthquake Administration, Lanzhou 730000, China
}

Correspondence should be addressed to Lanmin Wang; wanglm@gsdzj.gov.cn

Received 16 June 2019; Revised 24 September 2019; Accepted 28 September 2019; Published 5 November 2019

Academic Editor: Hamid Toopchi-Nezhad

Copyright (C) 2019 Xiaojun Yin and Lanmin Wang. This is an open access article distributed under the Creative Commons Attribution License, which permits unrestricted use, distribution, and reproduction in any medium, provided the original work is properly cited.

\begin{abstract}
Shaking table tests were performed to investigate whether the coupling effect of rainfall and earthquake induces the loess slope instability. The loess slope model was made by using the similarity ratio based on a real slope. Artificial rainfall was carried out, and then seismic waves were loaded step by step to adopt a large shaking table of $4 * 6 \mathrm{~m}$. The displacement in $x, y$, and $z$ directions and absolute displacement of loess slope $\left(u_{x}, u_{y}, u_{z}\right.$, and $\left.u_{a}\right)$ were measured to use the XTDIC displacement test system in $50 \mathrm{~s}$ when the seismic waves at peak acceleration were loaded to 600 gal, 700 gal, 800 gal, 976 gal, and 1300 gal, respectively. The results showed that the acceleration of one point was much larger than the other. $u_{a}$ occurred when seismic waves were loaded to 700 gal, and $u_{a \max }$ was obtained when seismic waves were loaded to 1300 gal finally. The $u_{\max }$ would reach in $20 \sim 25 \mathrm{~s}$, which was the period of amplitude peak. The theoretical value was larger than the test value for the critical seismic acceleration coefficient. Loess liquefaction appeared along the slope top under 976 gal loading condition. The change of displacement in $y$ direction is the main reason for the curve trajectory of the sliding block, and the displacement differences of adjacent measuring points are the main reason for the formation of the sliding block. This study can provide a theoretical basis for loess slope design and risk management.
\end{abstract}

\section{Introduction}

The assessment of displacements developed during slope failures is an important aspect of slope stability analysis, especially in cases of earthquake-induced failures where the factor of safety may vary significantly during motion. In such cases, the exact variation of the factor of safety with time is not as indicative a description of slope failure as the resulting displacement of the slope can be.

Permanent seismic movement of slopes can be separated into at least two stages [1]: in the first stage, which is coseismic, gravity in combination with transient seismic forces may bring about temporary instability and permanent displacements on a failure surface, and the second stage, which is postseismic, follows immediately after the earthquake and causes large movement when, as a result of the first stage, the strength on the slip surface is reduced to a residual value that is less than what is required to maintain static equilibrium.

The sliding-block method, initially proposed by Newmark [2], forms the basis of simple models for predicting permanent coseismic displacements of slopes. The slidingblock model is generally successful in estimating small ground deformations without earthquake-induced loss of strength by Whitman [3]. However, when the ground displacement is large, it is not accurate, primarily because of earthquake-induced loss of strength in saturated soils and changes of the geometry of the soil mass towards a gentler 
inclination. Two-block and multiblock sliding models have been proposed and solved by some researchers [4-6].

In 2013, some loess landslides were triggered by the Min-Zhang Ms 6.6 earthquake (MZC-Ms 6.6), Yongguang Village in Gansu Province. The landslide is a typical example of loess landslide induced by the coupling effect of rainfall and earthquake. Wang et al. [7] have studied the dynamic mechanical effects of loess slope under the coupling effect of rainfall and earthquake and analyzed the changes of acceleration, earth pressure, and pore pressure when loess liquefied under a certain seismic condition.

However, several problems are not solved when loess landslide is induced by the coupling effect of rainfall and earthquake. For example, what is the relationship between sliding displacement and seismic acceleration for loess slope? How to vary the dynamic displacement of loess slope change with cyclic time? What are the influencing factors of critical seismic acceleration? How to form sliding blocks and sliding path of loess slope and so on? There are few reports about these problems.

To solve these problems, the shaking table test of the remolded loess slope is carried out. The sliding displacement changes with loading time are accurately measured with Shanghai optical measuring instrument (XTDIC displacement measuring system) for the first time. The test is conducted by considering the following three aspects: firstly, the displacement is measured in $x, y$, and $z$ directions of loess slope under five seismic wave conditions; secondly, the relationship is analyzed between sliding displacement and seismic acceleration of loess slope; and thirdly, the formation of sliding blocks, sliding distance of the blocks, and influence of sliding displacement on loess slope stability are discussed under the coupling effect of rainfall and earthquake. The research results are of great significance for the stability analysis, design, control, and safety avoidance distance of landslide.

\section{Shaking Table Test}

The geological conditions of the landslides induced by MZCMs 6.6, shown as Figure 1, were analyzed. The prototype of the test model adopted one natural loess slope which lies in Shanzidun Village, Lanzhou New District. The slope height is about $7 \mathrm{~m}$, and the slope angle is about $20^{\circ}$. The soil is Malan loess $\left(Q_{3}\right.$ loess), which is used to model the prototype for the test. The natural loess slope for five consecutive days of artificial rainfall test, including heavy, moderate, and light, and the total rainfall was about $684.5 \mathrm{~mm}$. These results of the infiltration test showed that the maximum permeability depth of the slope was about $1290 \mathrm{~mm}$ and the minimum permeability depth was about $710 \mathrm{~mm}$. The maximum humidity was $23 \%$, and the minimum humidity was about $19 \%$ in the permeability area of the loess slope (detailed results will be published in another paper). Therefore, the test of the loess slope model adopted the results of the infiltration test in which the rainfall intensity was $15 \mathrm{~mm} / \mathrm{h}$ and the total rainfall was $50 \mathrm{~mm}$. The penetration depth of the slope surface was about $25 \mathrm{~cm}$, and the moisture content was

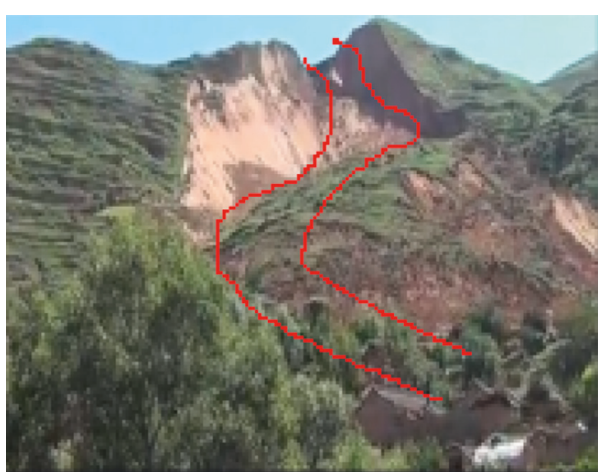

Figure 1: Loess landslide induced by the Min-Zhang Ms 6.6 earthquake.

$17 \% \sim 23 \%$. The whole slope surface of the model was complete and without crack, collapse, and other damage.

2.1. Introduction for the Large Shaking Table. The test adopted the large shaking table in the Lanzhou Institute of Seismology, China Earthquake Administration, as shown in Figure 2. The size is $4 \mathrm{~m} \times 6 \mathrm{~m}$, the maximum bearing capacity is $25 \mathrm{t}$, the maximum acceleration is $1.7 \mathrm{~g}$, and the maximum speed is $1.5 \mathrm{~m} / \mathrm{s}$. Regular and irregular waves (including seismic waves and shock waves) can be input, and the range of effective frequency is $0.1 \mathrm{~Hz} \sim 50 \mathrm{~Hz}$. The test adopted a rigid sealed model box, whose inner box size is $2.8 \mathrm{~m} \times 1.4 \mathrm{~m} \times 1.8 \mathrm{~m}$.

2.2. The Size of Slope Model. The model is shown in Figure 3, and the width of the slope model is $1400 \mathrm{~mm}$. Two layers of plastic foam plate $(2 \mathrm{~cm}$ thick) were laid on the sides of the model to reduce the boundary effect along the direction of vibration.

\subsection{The Layout of Displacement Measuring Points for Loess} Slope. The numbers of measuring points of the slope model are shown in Figure 4, which consists of 8 rows and 7 columns, total of 56 measuring points on the slope surface. The width of each column is $175 \mathrm{~mm}$ and the width of each row is about $222 \mathrm{~mm}$.

2.4. Similarity Ratio of the Slope Model. The loess slope model composed of Malan loess (pure $Q_{3}$ loess) from a hillside of New District, Lanzhou City. The soil parameters are shown in Table 1, and the similarity ratio is $10: 1$. According to the main purpose of the test, the remodel loess of on-site was used to a model material because the particle composition was one of the main internal factors of loess structure. The soil of the slope model has certain structure and structural strength as long as the density and cohesion of remodel loess are basically similar to on-site $[8,9]$.

2.5. The Direction of Shaking Table Test for Loess Slope Model. The displacement direction of the measuring point in the test is shown in Figure 5. 


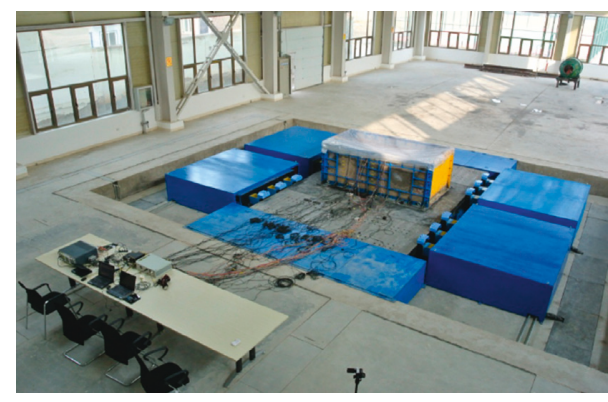

Figure 2: The large shaking table.

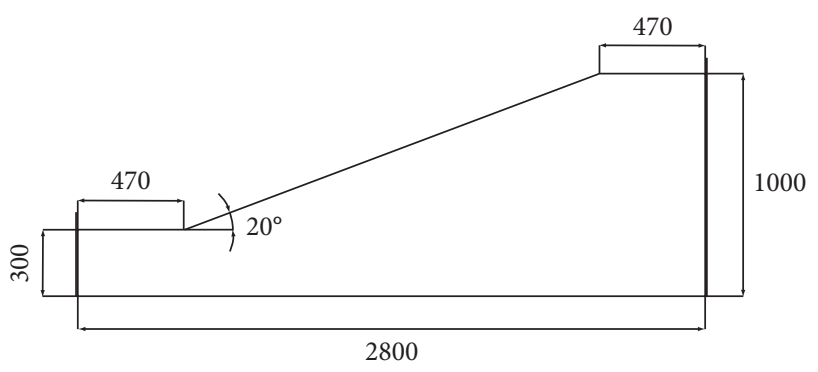

FIgURE 3: Size of the slope model.

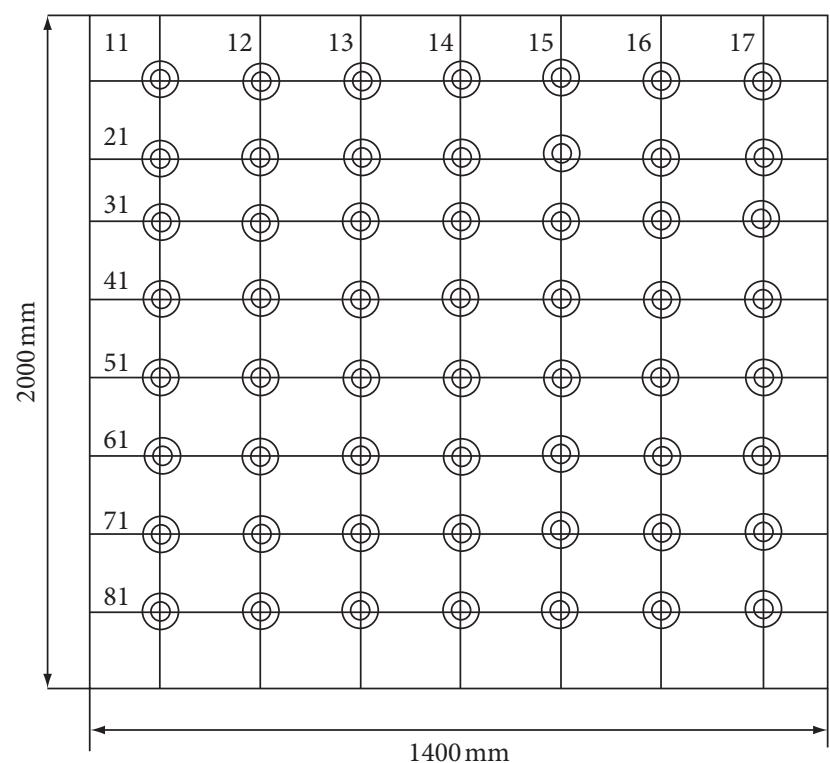

Figure 4: Layout of displacement measuring points for slope surface.

\subsection{Loading Wave of Shaking Table Test}

2.6.1. Sine Wave $(3 \sim 50 \mathrm{~Hz})$. The sine wave was input by scanning frequency, and $20 \mathrm{gal}\left(1 \mathrm{gal}=0.01 \mathrm{~m} / \mathrm{s}^{2}\right)$ sine wave was input to determine the natural frequency of the slope model. The time-history diagram of 200 gal sine wave acceleration is shown in Figure 6.

2.6.2. The Wave of Min County. The wave of Min County is the time history of the main shock acceleration, which is
TABLE 1: Material similarity ratio.

\begin{tabular}{lcccc}
\hline Types & $\begin{array}{c}\text { Water } \\
\text { content }(\omega / \%)\end{array}$ & $\begin{array}{c}\text { Density } \\
\left(\rho / \mathrm{kg} \cdot \mathrm{m}^{-3}\right)\end{array}$ & $\begin{array}{c}\text { Cohesive } \\
\text { force }(c / \mathrm{kPa})\end{array}$ & $\begin{array}{c}\text { Angle of } \\
\text { internal } \\
\text { friction } \\
\left(\varphi /{ }^{\circ}\right)\end{array}$ \\
\hline $\begin{array}{l}\text { Prototype } \\
\text { value }\end{array}$ & $4.1 \sim 5.6$ & $1.28 \sim 1.45$ & $30 \sim 60$ & $26 \sim 48^{\circ}$ \\
$\begin{array}{l}\text { Design } \\
\text { value }\end{array}$ & 6 & 1.31 & 5 & 40 \\
\hline
\end{tabular}

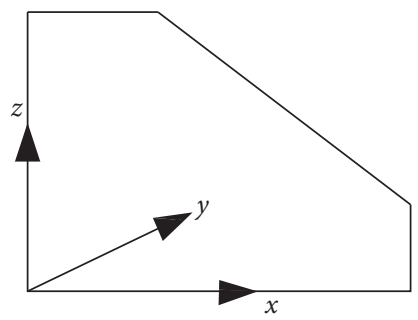

FIGURE 5: Displacement monitor direction.

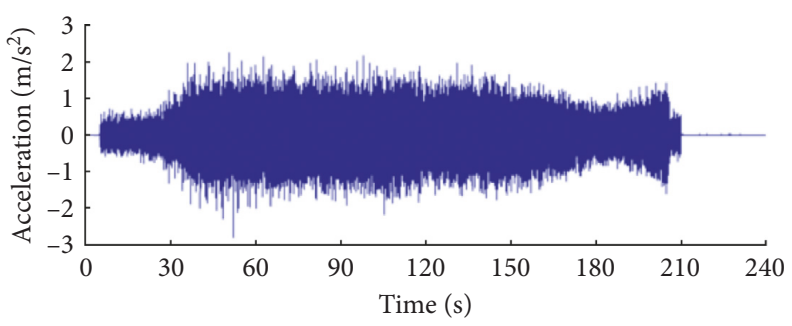

FIgURe 6: Sine wave.

recorded in the strong ground motion station of Min County during the Min-Zhang Ms 6.6 earthquake on July 22, 2013. The wave consists of a vertical component and a horizontal component as shown in Figure 7.

\section{Analysis of Dynamic Parameters of Loess Slope}

3.1. The Seismic Acceleration Amplification Effect of Loess Slope. The slope has its inherent critical acceleration coefficient $k_{c}$. When the seismic acceleration coefficient, $k(t)$, is larger than the critical acceleration coefficient, Kc, the slope may fail or slip to develop a permanent displacement.

According to the existing research results and field observations $[10,11]$, the acceleration of slope usually increases rapidly $k(t)>1$ or $k(t)<-1$ as earthquake occurs, which is called the acceleration amplification effect. Therefore, studying the seismic acceleration amplification factor is of great significance for sliding displacement of loess slope.

3.2. The Seismic Acceleration Amplification Factor of Loess Slope. The accelerations $\alpha$ were measured by the acceleration sensor arranged in the loess slope model when the seismic wave was input. The acceleration amplification 


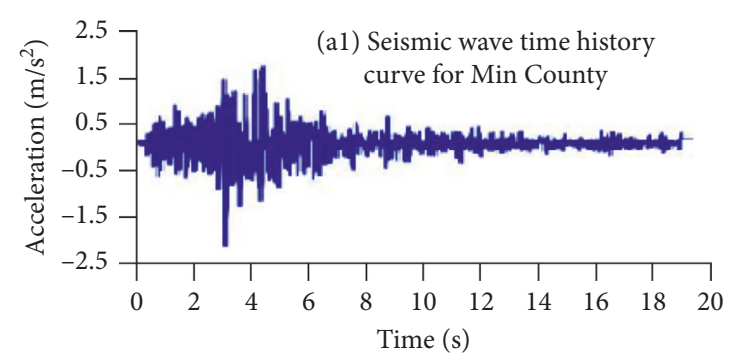

(a)

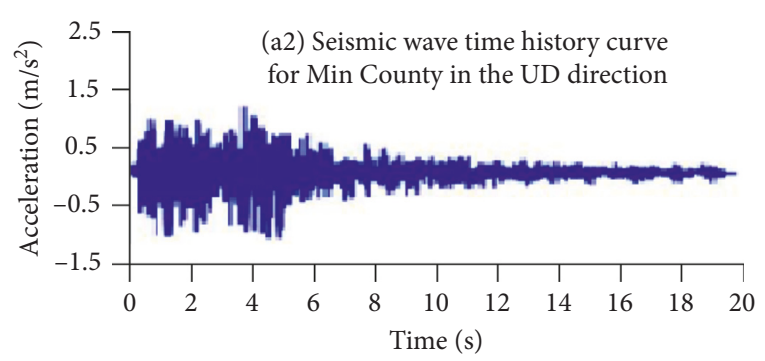

(b)

Figure 7: Seismic wave of Min County.

factors among five measuring points along the loess slope model are shown in Figure 8. Measuring points 1, 2, 3, 4, and 5 refer to $A_{21}, A_{31}, A_{41}, A_{51}$, and $A_{61}$, respectively, as shown in Figure 9 (including amplification factor for the positive and negative acceleration).

3.3. The Analysis of $\mathrm{Q}_{3}$ Loess Liquefaction. Figure 10 shows the time histories of acceleration, pore pressure, and earth pressure on the slope shoulder where liquefaction occurs in the position of No. A61. The overall trend of pore pressure curve under 976 gal loading wave was similar to that under 700 gal wave, and the change of the pore pressure was small in $0 \sim 20 \mathrm{~s}$. However, as under 976 gal loading condition, pore pressure rises rapidly, the acceleration time history gradually deviates from the baseline position, and more "spikes" were appeared (typical liquefaction mark) in 21 30 s. Then pore pressure was basically close to the overlying pressure $(0.21 \mathrm{kPa})$. The earth pressure increased monotonously with a small range of undulation. These phenomena indicated that soil properties have been obviously changed, that is, soil liquefaction.

\section{Displacement of Loess Slope Shaking Table Test}

4.1. The Monitoring Displacement of Loess Slope Model. The XTDIC displacement test system (optical measurement) of the Quanshi Software system (Shanghai) Co., Ltd., was adopted and the layout of the measuring point is shown in Figure 4. The displacement of loess slope was recorded under five operating conditions, which were loading waves of 600 gal, 700 gal, 800 gal, 976 gal, and 1300 gal, successively. The monitoring time of each input wave was about $50 \mathrm{~s}$, and the instantaneous displacement of the measuring point in $x$, $y$, and $z$ directions and the absolute displacement (namely, $u_{x}, u_{y}, u_{z}$, and $u_{a}$ ) can be recorded. Each operation was an independent testing process, it started at $0 \mathrm{~s}$ and ended at $50 \mathrm{~s}$, and then the displacement would be retested in the next operation.

4.2. The Displacement Analysis of Loess Slope. The measurement point of the loess slope model (location of no. 76 measuring point in Figure 4) was studied because of the degree of macroscopic fracture and sliding distance on the slope face. Due to the vibration (mechanical vibration) of the shaking table itself, the displacement of these measuring points is not considered during the initial loading wave (in a fraction of a second).

4.2.1. The Displacement of Loess Slope at the $600 \mathrm{gal}$. As the time of the seismic wave goes on, obvious cracks have appeared on the slope surface as shown in Figure 11. $u_{x}, u_{u}$, and $u_{z}$ all are equal to 0 when the loading time is $0 \sim 23.6 \mathrm{~s}$. However, $u_{x}, u_{y}$, and $u_{z}$ are equal to $365.43 \mathrm{~mm}$, $-370.49 \mathrm{~mm}$, and $-2044.38 \mathrm{~mm}$, respectively, when the loading time is $23.9 \mathrm{~s}$ and finally tends to be relatively constant. $u_{a}$ is still equal to 0 under the loading wave condition. Figure 12 shows $u_{x}, u_{y}$, and $u_{z}$ in $0 \sim 50 \mathrm{~s}$.

4.2.2. The Displacement of Loess Slope at the $700 \mathrm{gal}$. $u_{x}, u_{y}$, $u_{z}$, and $u_{a}$ are given at the $700 \mathrm{gal}$ in Figure 13. As can be seen from the macroscopic picture, the cracks gradually increased and a rupture block appeared on the slope surface.

4.2.3. The Displacement of Loess Slope at the $800 \mathrm{gal} . u_{x}, u_{y}$, $u_{z}$, and $u_{a}$ are given at the $800 \mathrm{gal}$ in Figure 14 . From the figure, the space of rupture blocks is about $3-5 \mathrm{~cm}$, and the numbers of blocks were obviously increased.

4.2.4. The Displacement of Loess Slope at the $976 \mathrm{gal}$. Figure 15 gives the analysis of $u_{x}, u_{y}, y_{z}$, and $u_{a}$ at the 976 gal. From the macroscopic view, there were many rupture blocks on the slope shoulder and near the slope toe. There was obvious convexity and concave between the blocks. The spacing of the blocks increased significantly, and it also appeared obvious on both sides of the slope. Loess liquefaction occurred on the slope surface.

4.2.5. The Displacement of Loess Slope at the $1300 \mathrm{gal}$. Figure 16 gives the analysis of $u_{x}, u_{y}, u_{z}$, and $u_{a}$ at the 1300 gal. At the time, the rupture blocks were complex, a lot of sliding blocks were formed, and the spacing and the drop of blocks were very obvious. The fall of sliding interblock is about $3 \sim 5 \mathrm{~cm}$. The loess presented a clear muddy flow with water, owing to loess liquefaction. 


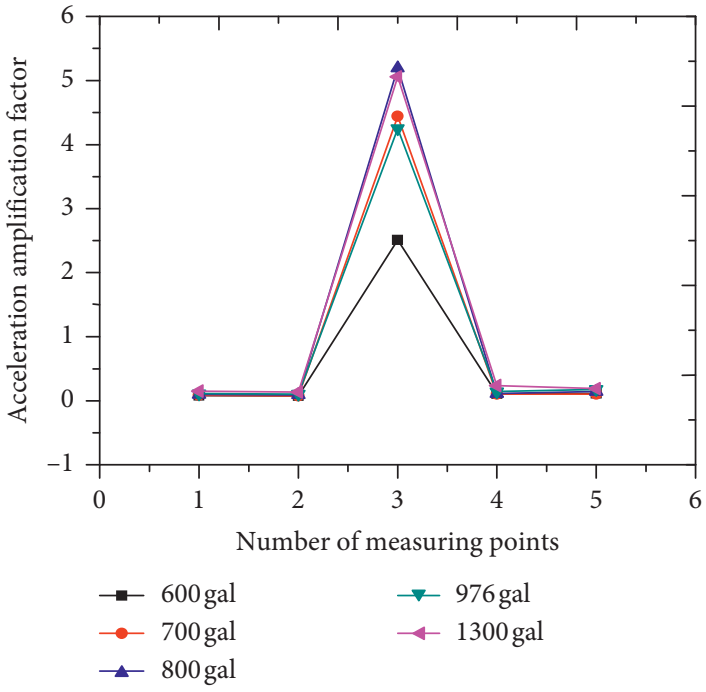

(a)

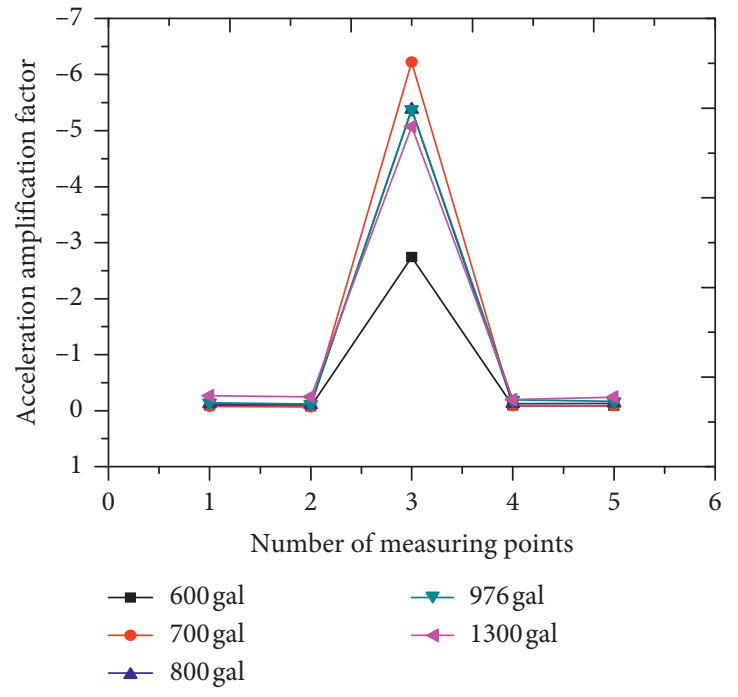

(b)

FIgURE 8: Acceleration magnification factor of loess slope.

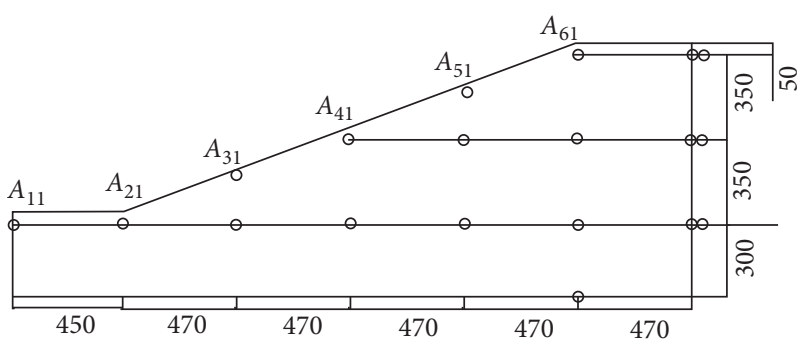

Figure 9: Cross-section of the loess slope model.

4.3. Comparison of Displacement of Loess Slope in the Same Row. These measuring points (measuring points 1, 2, 3, 4, 5, 6, and 7 in Figure 17 refer to from no. 61 to no. 67 in Figure 4) were analyzed in order to study the position of the rupture slip on the slope surface. The values of all measuring points showed maximum displacement under the corresponding loading conditions. The displacement of no. 63 failed to read under the 1300 gal loading wave. The analysis of $u_{y}, u_{z}$, and $u_{a}$ is given as presented in Figure 17 .

4.4. Comparison of Displacement of Loess Slopes in the Same Column. With the same reason as above in Section 4.3, the measuring points in the sixth column were studied, and measuring points $1 \sim 8$ referred to no. $16 \sim$ no. 86 in Figure 4 . The analysis of $u_{x}, u_{y}$, and $u_{a}$ is given as shown in Figure 18.

\section{The Relationship between Seismic Acceleration and Displacement}

According to the Newmark block analysis method [12], the following equation gives the relationship between the sliding displacement of the slope block and the acceleration:

$$
\ddot{u}_{0}=z_{0}\left(k(t)-k_{\mathrm{c}}\right) \cdot g \text {, }
$$

where $u_{0}$ is the sliding displacement of the slope block, $\varphi$ is the angle of internal friction, $\alpha$ is the slope angle of loess slope, $k_{c}$ is the critical acceleration factor of earthquake, and $k(t)$ is the seismic acceleration factor, $z_{0}=$ $(\cos (\varphi-\alpha) / \varphi)$

For a given geometry of the soil slope and soil parameters, the $k_{\mathrm{c}}$ may be computed by the software Matlab 6.5.

5.1. The Critical Seismic Acceleration Factor of Loess Slope. The critical acceleration for a given earth slope section was much simpler than the computation of the static factor of safety. The critical acceleration factor $k_{\mathrm{c}}$ was obtained as the first part of the solution towards the static factor of safety. It can therefore be said that the $k_{\mathrm{c}}$ method of solution was both physically accurate and computationally advantageous method.

Absolute displacement occurred when the loading wave is at $700 \mathrm{gal}$; it indicated that the loess slope has been damaged. The sliding displacement indicated that $k(t)$ of the loading wave exceeded $k_{\mathrm{c}}$ of the slope. The value of $k_{\mathrm{c}}$ can be derived to use the measured experimental data. Table 2 gives the comparison of $k_{\mathrm{c}}$ between the test value and theoretical value for different heights, of the slope $H$.

5.2. The Relationship between Maximum Displacement and Instability of Loess Slope. The magnitude of the critical sliding displacement is depended on the ground motion, the composition, and the characteristics of the loess slope. Many researchers have given different critical sliding displacements for different landslide. The sliding slope belongs to a shallow landslide, so according to Jibson et al. results [13], the slope was unstable and damaged at a sliding displacement of $2 \sim 15 \mathrm{~cm}$. The displacement is more than $2 \mathrm{~cm}$ when the seismic wave is loaded to $700 \mathrm{gal}$ at $22.1 \mathrm{~s}$. The displacement of no. 76 is $2.01 \mathrm{~cm}$ at $22 \mathrm{~s}$. $u_{a \max }$ of no. 62 is 


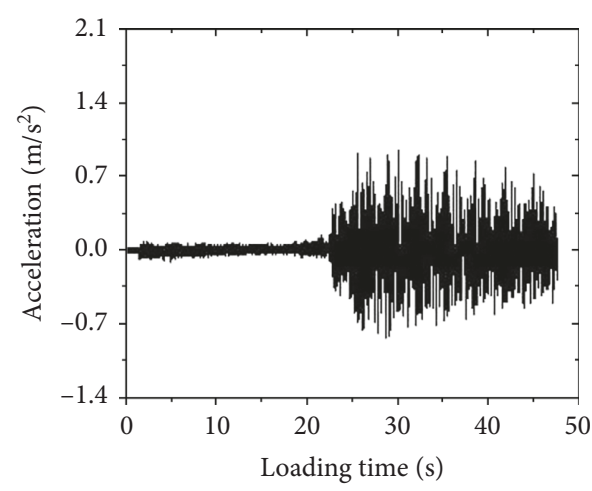

(a)

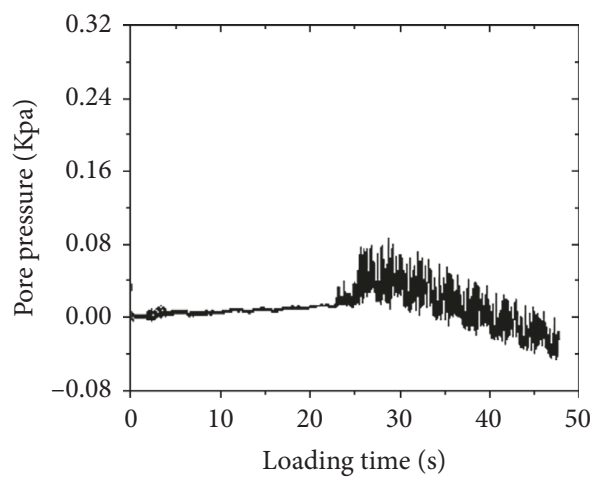

(c)

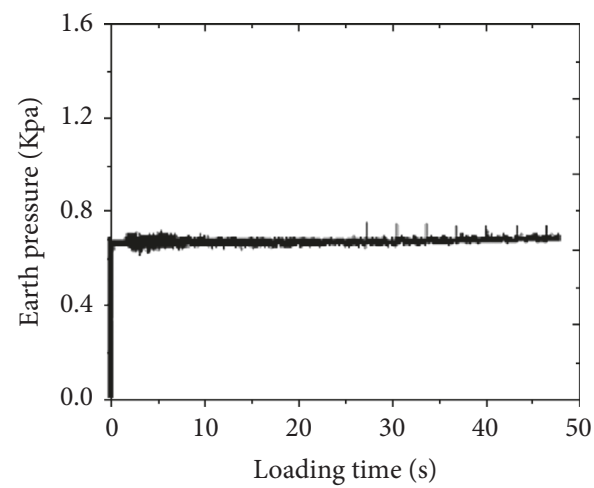

(e)

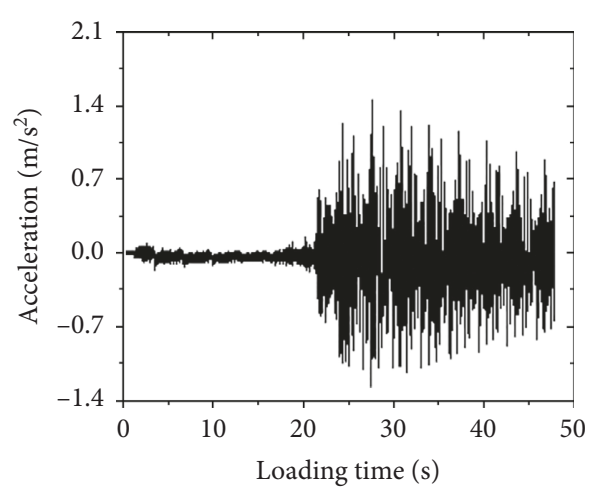

(b)

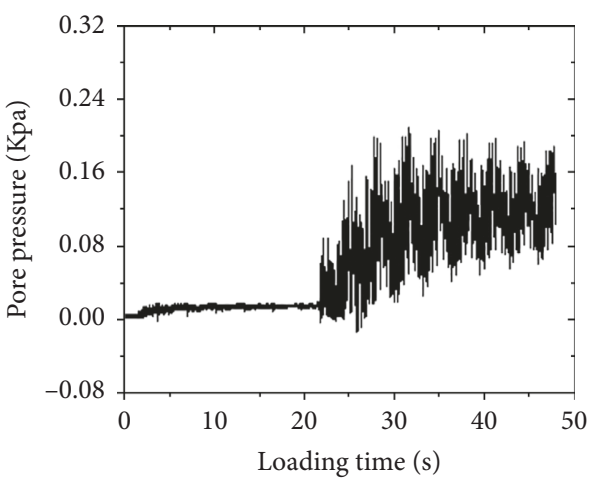

(d)

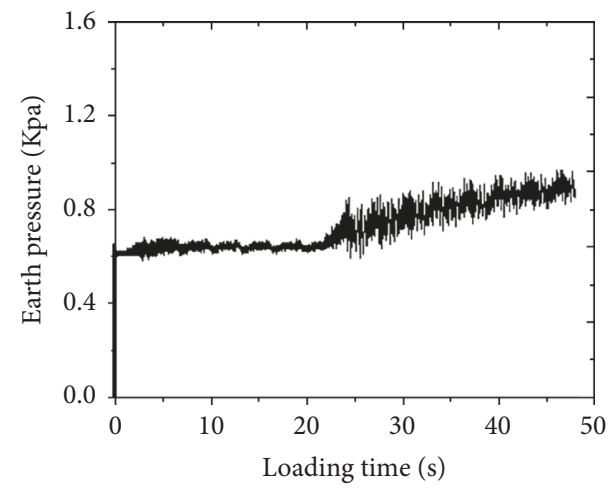

(f)

FIGURE 10: Time history of acceleration, pore pressure, and earth pressure on the slope shoulder.

$3.63 \mathrm{~cm}$ at $23.3 \mathrm{~s}$, and all displacements are more than $2 \mathrm{~cm}$ when the loading time exceeds $23.9 \mathrm{~s}$. It indicates that the location of no. 62 had most serious damage.

\section{Discussions}

6.1. Data Analysis of the Test. There are two main principles for choice of measure points: firstly, the complete data were adopted because data of some measure points were read incomplete or not read at all for some unknown causes, and secondly, based on the degree of surface damage of the loess slope model and the experience of a number of on-site landslides, the key points of the slope model were selected.

Figure 8 shows that location of no. 3 appears to have a very large acceleration. A large number of on-site

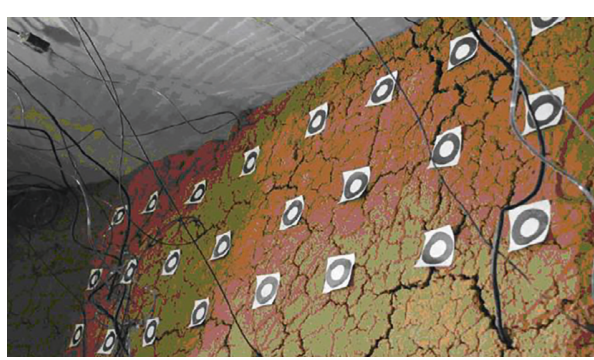

Figure 11: Loess slope surface at the 600 gal.

monitoring and test results showed $[10,14]$ that the loess site developed amplification effect during the earthquake. The $Q_{3}$ loess structure was damaged and shear strength 


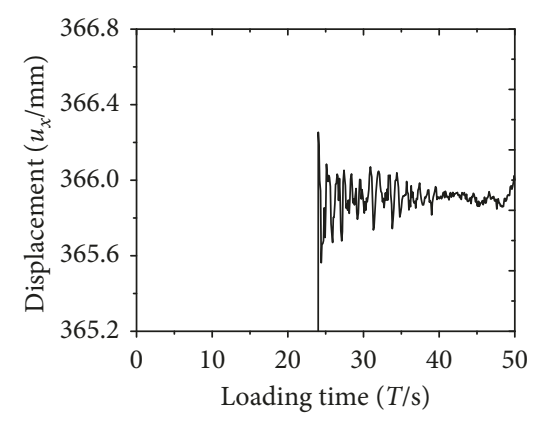

(a)

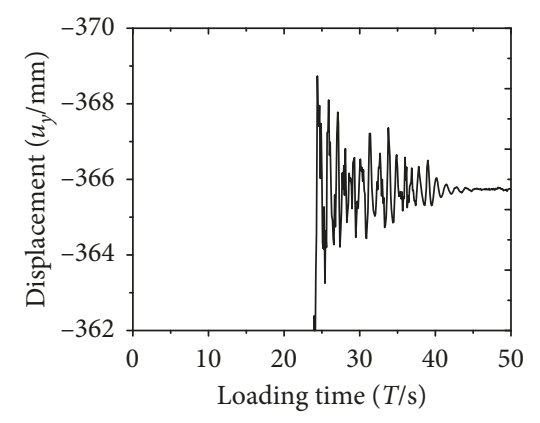

(b)

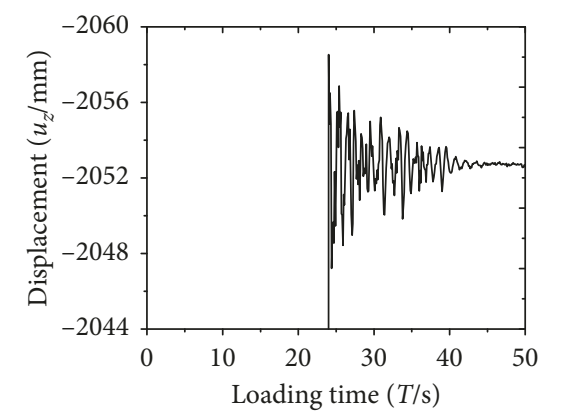

(c)

FigURE 12: Variation of displacement with loading time.

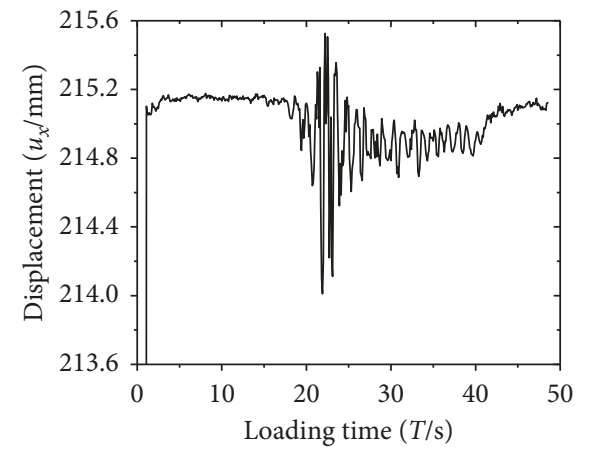

(a)

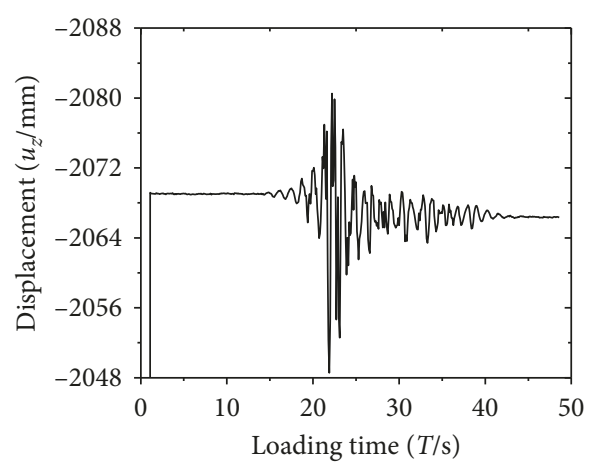

(c)

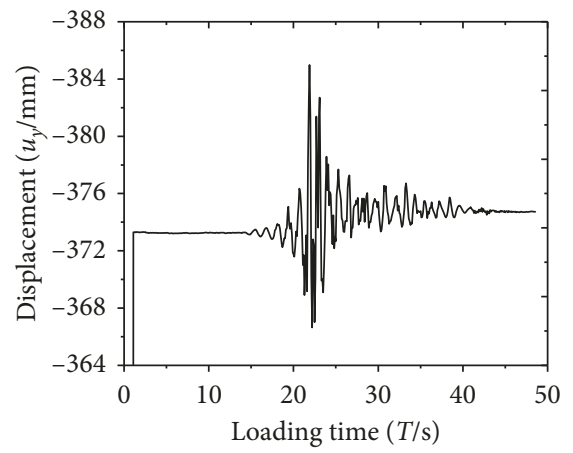

(b)

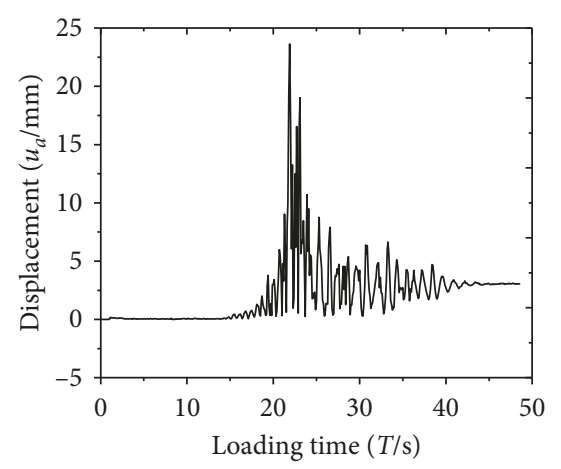

(d)

FIGURE 13: Variation of displacement with loading time.

reduced due to increase of loading strength. The acceleration is very large when natural vibration frequency of loess slope is much closer to or equal to load frequency, which is the acceleration amplification effect. Wang et al. [11] have proved the phenomenon by large shaking table test. 


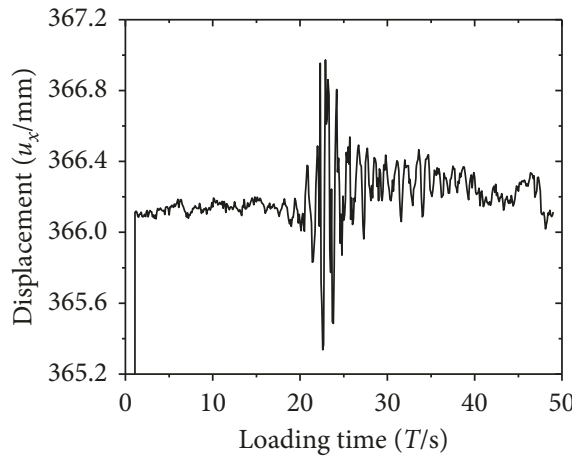

(a)

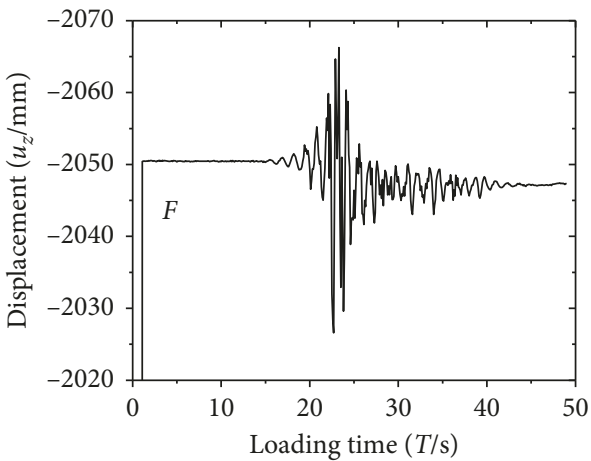

(c)

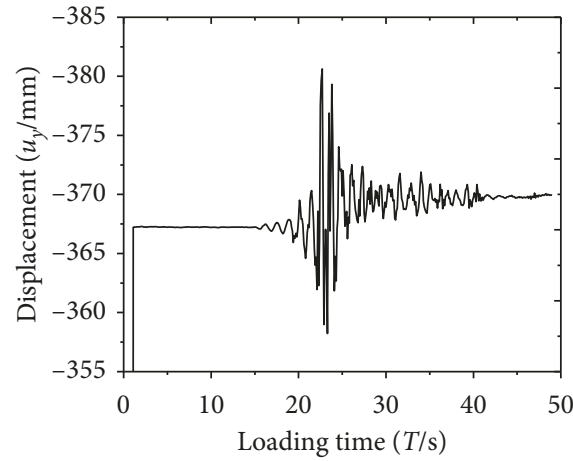

(b)

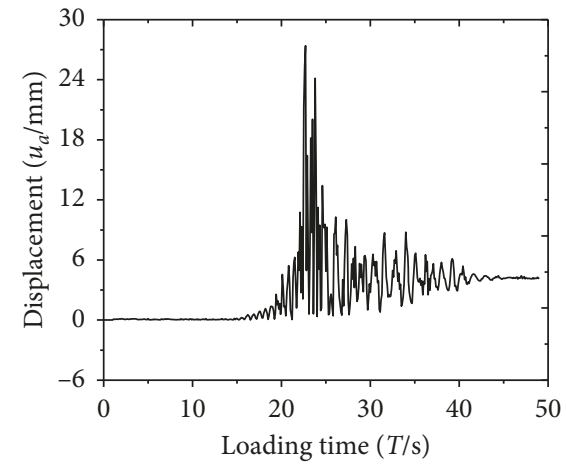

(d)

FIGURE 14: Variation of displacement with loading time.

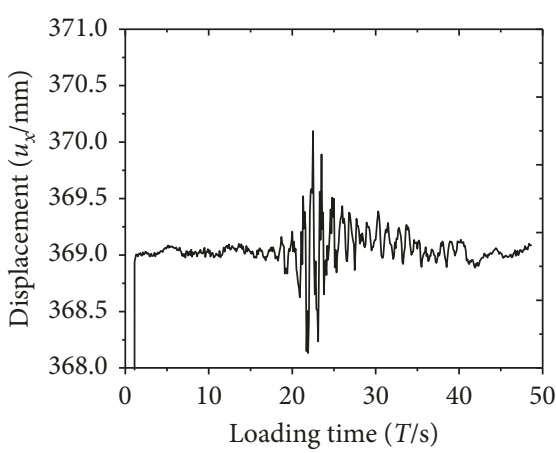

(a)

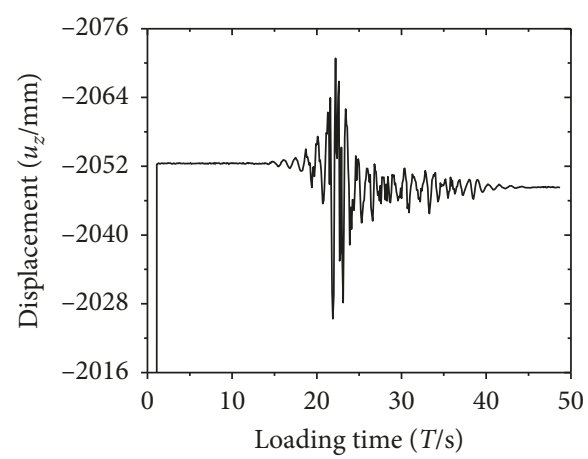

(c)

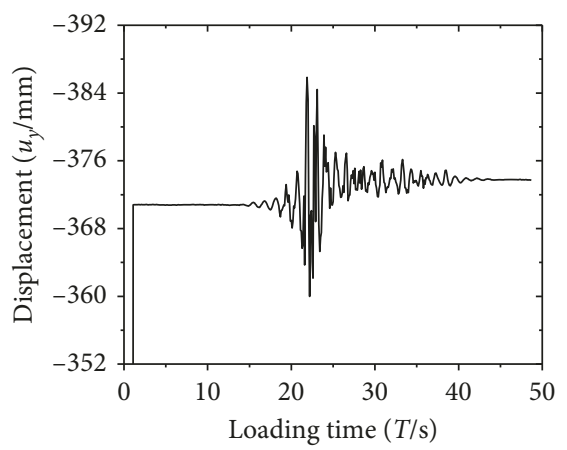

(b)

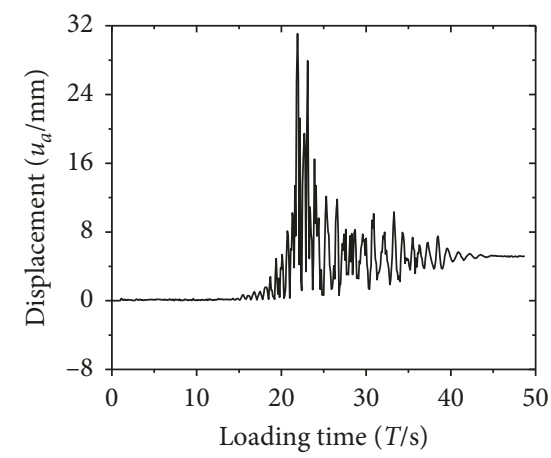

(d)

FIgURE 15: Variation of displacement with loading time. 


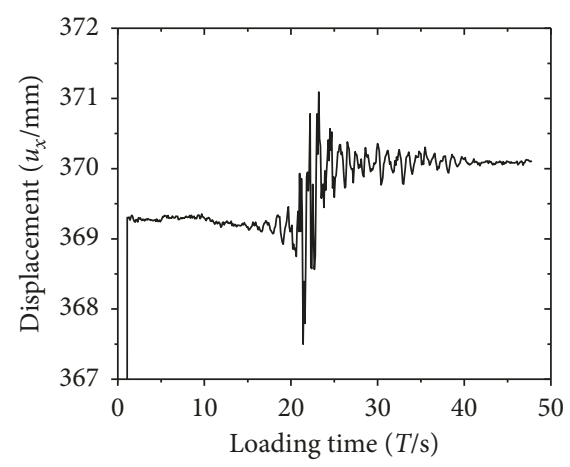

(a)

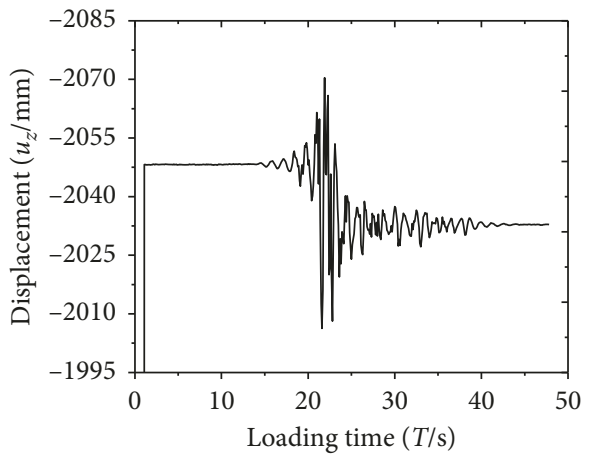

(c)

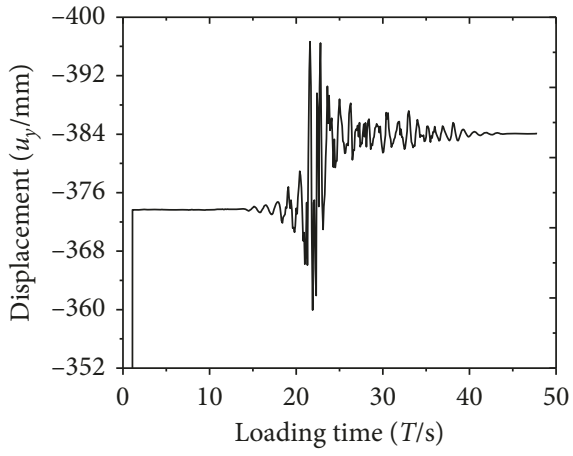

(b)

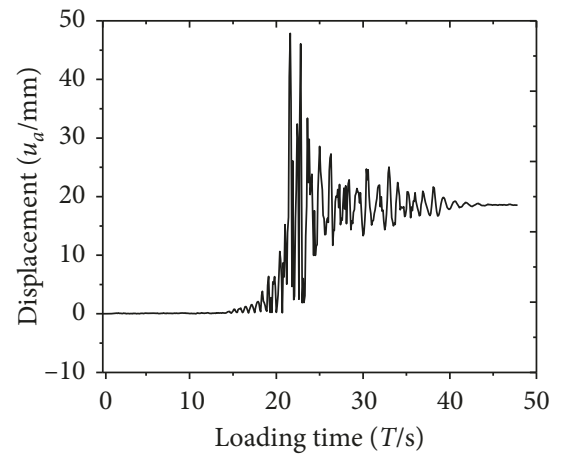

(d)

Figure 16: Variation of displacement with loading time.

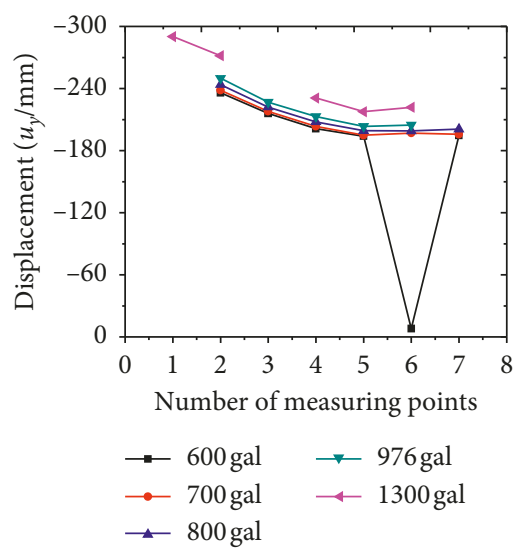

(a)

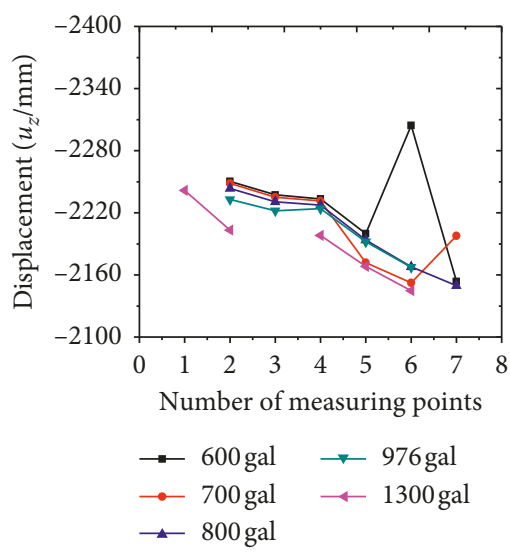

(b)

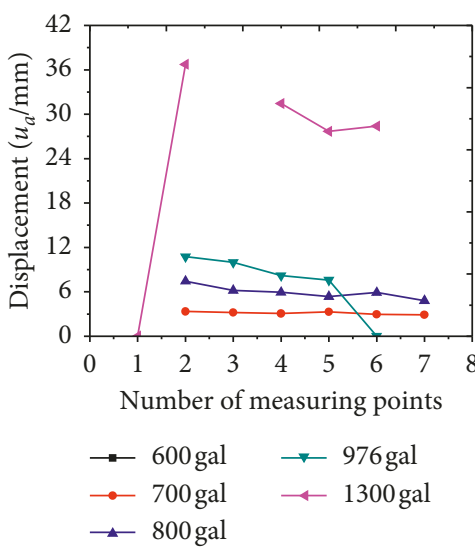

(c)

Figure 17: Variation of displacement with location.

Figure 10 shows that the pore pressure has been changed significantly and is close to overlying pressure. Many phenomena of "spike" arise from the acceleration. The earth pressure is average monotonous increased on the undulating base. The course is termed loess liquefaction.

It can be seen from Figures 12-16 and 19-22 that all the maximum peak values of acceleration, $u_{x}, u_{y}, u_{z}$, and ua appear during the loading time of 20-25s, where resonance might occur. $u_{z}$ is far greater than $u_{x}$ and $u_{y}$. As loading to 700 gal, $u_{x}$ sharply reduces, $u_{y}>0$, then appears to $u_{a}>0$, and it indicated that blocks of loess slope began to slip. $u_{a}$ basically increases with an increase in loading intensity.

Figure 21 shows that the change of displacement in no. 66 is obviously different from the other; it indicates that the location is easily damaged, and the position is at first damaged from the image of loess slope model. $u_{z}$ slowly increases as loading more than 600 gal. $u_{a}$ sharply increases $\left(u_{a \max }=318 \mathrm{~mm}\right)$ at the 1300 gal; it shows that the velocity of sliding blocks is far greater than the other, and the velocity of sliding blocks sharply increases with increase in loading intensity. 


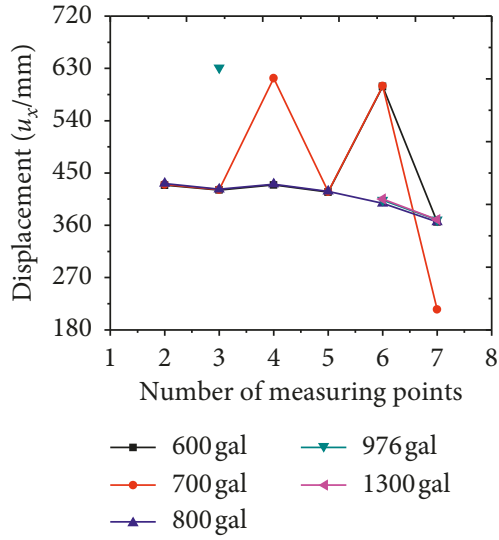

(a)

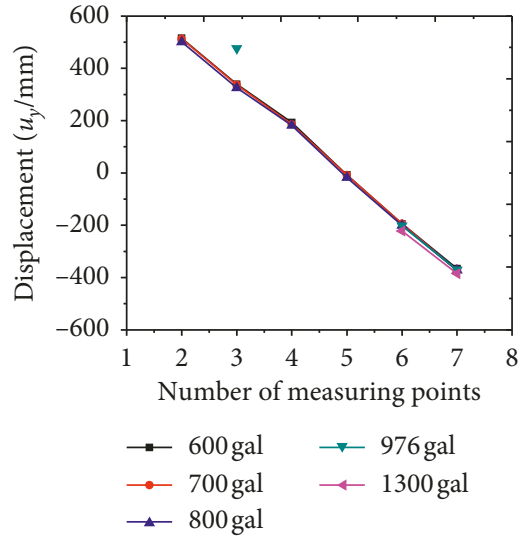

(b)

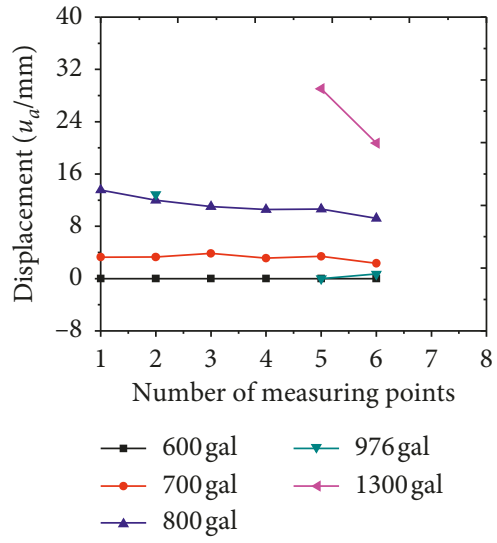

(c)

FIgURE 18: Variation of displacement with location.

TABLE 2: Critical seismic acceleration factor.

\begin{tabular}{lccc}
\hline Slope position & $H / 4$ & $2 H / 4$ & $3 H / 4$ \\
\hline Test value & 0.4 & 0.43 & 0.483 \\
Theoretical value & 0.392 & 0.411 & 0.463 \\
\hline
\end{tabular}

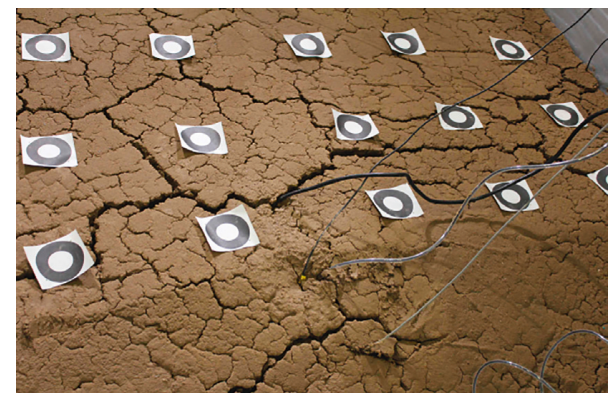

Figure 19: Loess slope surface at the $700 \mathrm{gal}$.

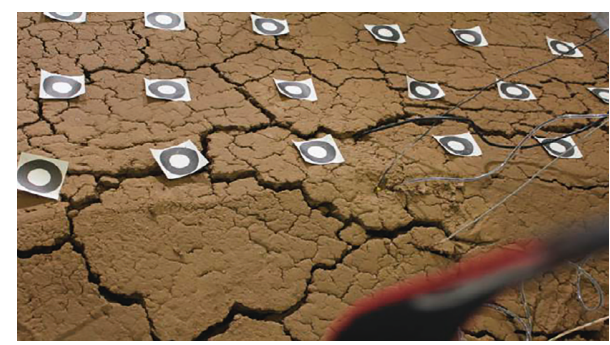

Figure 20: Loess slope surface at the 800 gal.

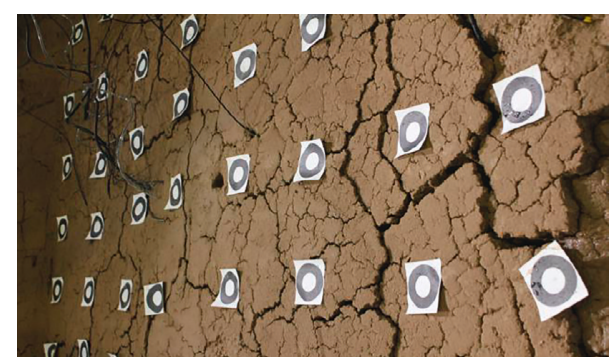

FIGURE 21: Loess slope surface at the 976 gal.

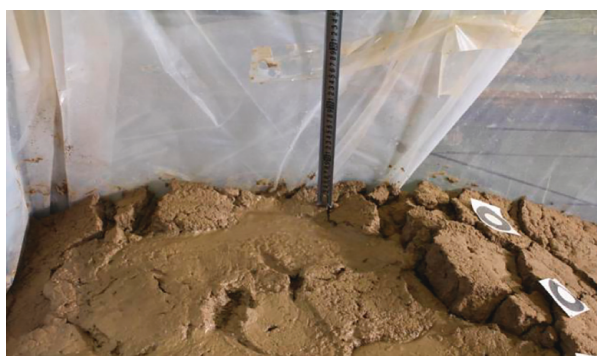

FIgURE 22: Loess slope surface at the 1300 gal.

Figure 22 shows that $u_{y}$ reduces first and then increases from slope top to slope toe, and positive and negative changes of $u_{y}$ indicate sliding blocks move along the curve. $u_{z}$ gradually reduces from slope top to slope toe. The changes of $u_{y}$ and $u_{z}$ are very small for different loading waves. $u_{x}$ sharply increases which indicates that sliding blocks appear on the slope surface.

It can be seen from Table 2 that the critical acceleration factor is different at different locations on the slope. Therefore, the location of the slope failure is also different during the earthquake.

6.2. Prediction of Maximum Displacement of the Sliding Block. Based on the results of the test, the maximum displacement of the sliding block is given in the following fitted function:

$$
u=7988 a^{2}+834.39 a-0.8505
$$

where $u$ is the maximum sliding displacement of the block, $\mathrm{m}$, and $a$ is the seismic acceleration, $\mathrm{m} / \mathrm{s}^{2}$.

6.3. The Analysis of Failure and Slip Path of Loess Slope. The coupling effect of rainfall and earthquake may be analyzed through two aspects: firstly, the $Q_{3}$ loess contains large amount of soluble minerals. The $Q_{3}$ loess structure was damaged and the shear strength was decreased due to solution under rainfall condition; secondly, seismic force exceeded loess shear force under earthquake condition. As a 
result, the coupling effect of rainfall and earthquake induced the failure and sliding of the loess slope.

Sliding blocks are formed as a result of different displacement difference $(\Delta u)$ in the same row and column. The displacement and trajectory of sliding blocks are depended on the geometry of sliding blocks. The test result is consistent with theoretical analysis by Stamatopoulos et al. [6].

However, the quantitative relationship between the coupling effect of rainfall and earthquake will be analyzed in future study.

\section{Conclusions}

Using the artificial rainfall and large-scale shaking table test under different ground motions, soil dynamic parameters and displacements of loess slope were monitored:

(1) The acceleration amplification effect is very obvious when the natural vibration frequency of loess slope is much closer to or equal to load frequency. The position of loess slope is also the most severe part of the damage.

(2) $u_{a}$ would arise as loading to $700 \mathrm{gal}$, which indicated that the loess slope began to fail during the seismic wave. Judging whether the slope is unstable according to $u_{a}$ is a reliable method for slope stability analysis.

(3) The displacement of loess slope is the result of the coupling of rainfall and earthquake and loess liquefaction.

(4) $u_{x \max }, u_{y \max }$ and $u_{z \max }$ are reached within loading time ( $t=20 \sim 25 \mathrm{~s})$, which is the loading peak period.

(5) The change of $u_{y}$ indicates that the sliding blocks slide along the curve, which is consistent with the field observation of the earthquake-induced loess slope instability.

(6) The sliding blocks are formed as a result of different displacement difference $(\Delta u)$ in the same row and column, which can provide reference for improving the theory of block analysis.

\section{Data Availability}

The data used to support the findings of this study are available from the corresponding author upon request.

\section{Conflicts of Interest}

The authors declare that there are no conflicts of interest regarding the publication of this paper.

\section{Acknowledgments}

This work was financially supported by the National Natural Science Foundation of China (Grant no. 51478444).

\section{References}

[1] N. Ambraseys and M. Srbulov, "Earthquake induced displacements of slopes," Soil Dynamics and Earthquake Engineering, vol. 14, no. 1, pp. 59-71, 1995.
[2] N. M. Newmark, "Effects of earthquakes on dams and embankments," Géotechnique, vol. 15, no. 2, pp. 139-160, 1965.

[3] R. V. Whitman, "Predicting earthquake-caused permanent deformations of earth structures," in Proceedings of the Wroth Memorial Symposium on Predictive Soil Mechanics, pp. 729741, Thomas Telford, Oxford, London, July 1992.

[4] C. A. Stamatopoulos, E. G. Velgaki, and S. K. Sarma, "Slidingblock back analysis of earthquake induced slides," Soils and Foundations, vol. 40, no. 6, pp. 61-75, 2000.

[5] C. A. Stamatopoulos, "Constitutive modeling of earthquakeinduced slides on clays along slip surfaces," Landslides, vol. 6, no. 3, pp. 191-207, 2009.

[6] C. A. Stamatopoulos, C. Mavromihalis, and S. Sarma, "Correction for geometry changes during motion of sliding-block seismic displacement," Journal of Geotechnical and Geoenvironmental Engineering, vol. 137, no. 10, pp. 926-938, 2011.

[7] L. M. Wang, X. W. Pu, Z. J. Wu et al., "The shaking table test of the instability sliding of loess slope under the coupling effects of earthquake and rainfall," Chinese Journal of Rock Mechanics and Engineering, vol. 36, no. s2, pp. 3873-3883, 2017, in Chinese.

[8] G. Lin, T. Zhu, and B. Lin, "Similar techniques for structural dynamic model test," Journal of Dalian University of Technology, vol. 40, no. 1, pp. 1-8, 2000.

[9] S. J. Shao, F. F. Zhou, and J. Y. Long, "Structural and quantitative parameters of undisturbed loess," Chinese Journal of Geotechnical Engineering, vol. 26, no. 4, pp. 531-536, 2004, in Chinese.

[10] L.-M. Wang, Z.-J. Wu, and K. Xia, "Effects of site conditions on earthquake ground motion and their applications in seismic design in loess region," Journal of Mountain Science, vol. 14, no. 6, pp. 1185-1193, 2017.

[11] L. M. Wang, X. W. Pu, Z. J. Wu et al., "Shaking table tests on dynamic response of loess slopes under coupling effects of earthquakes and rainfalls," Chinese Journal of Geotechnical Engineering, vol. 40, no. 7, pp. 1287-1293, 2018, in Chinese.

[12] C. A. Stamatopoulos and E. G. Velgaki, "Critical acceleration and seismic displacement of vertical gravity walls by a two body model," in Proceedings of the 4th International Conference on Recent Advances in Geotechnical Earthquake Engineering and Soil Dynamics, San Diego, CA, USA, March 2001.

[13] R. W. Jibson, E. L. Harp, and J. A. Michael, “A method for producing digital probabilistic seismic landslide hazard maps," Engineering Geology, vol. 58, no. 3-4, pp. 271-289, 2000.

[14] L. M. Wang and Z. J. Wu, "Influence of site condition on seismic amplification effect during the Wenchuan earthquake," Journal of Civil, Architectural \& Environmental Engineering, vol. 32, no. S2, pp. 175-178, 2010. 


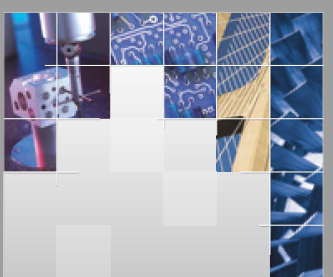

\section{Enfincering}
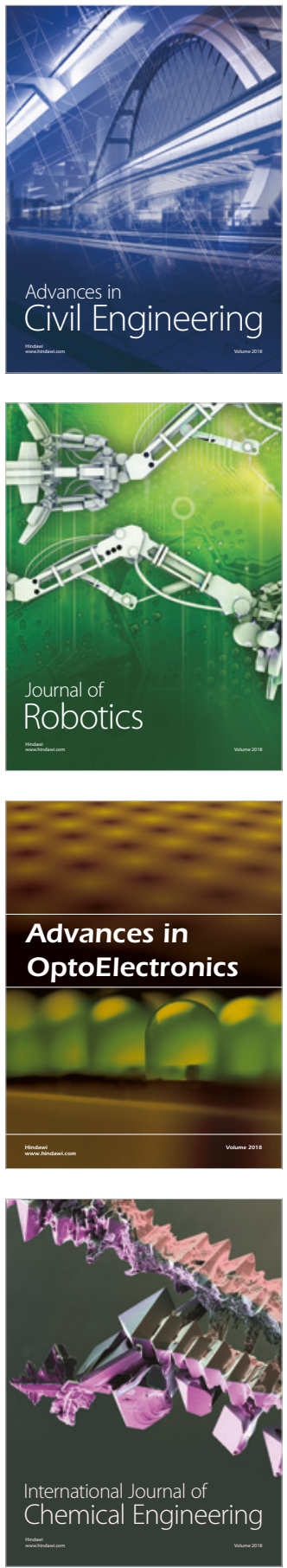

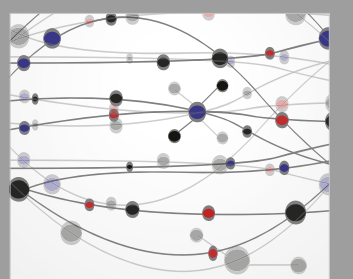

\section{Rotating \\ Machinery}

The Scientific World Journal

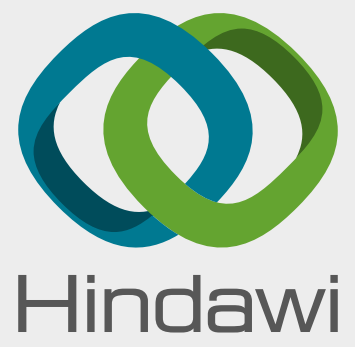

Submit your manuscripts at

www.hindawi.com
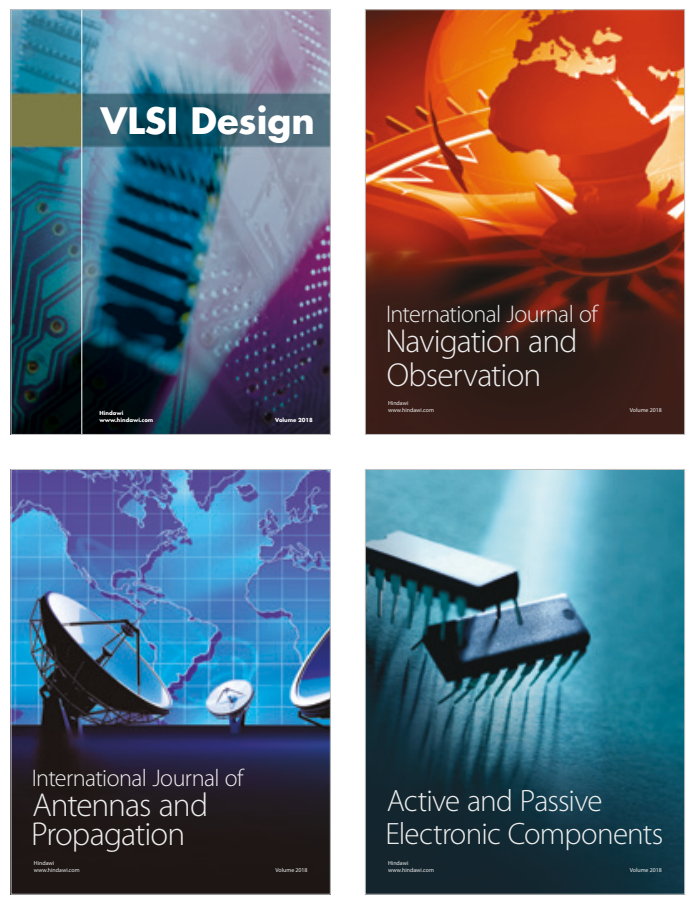
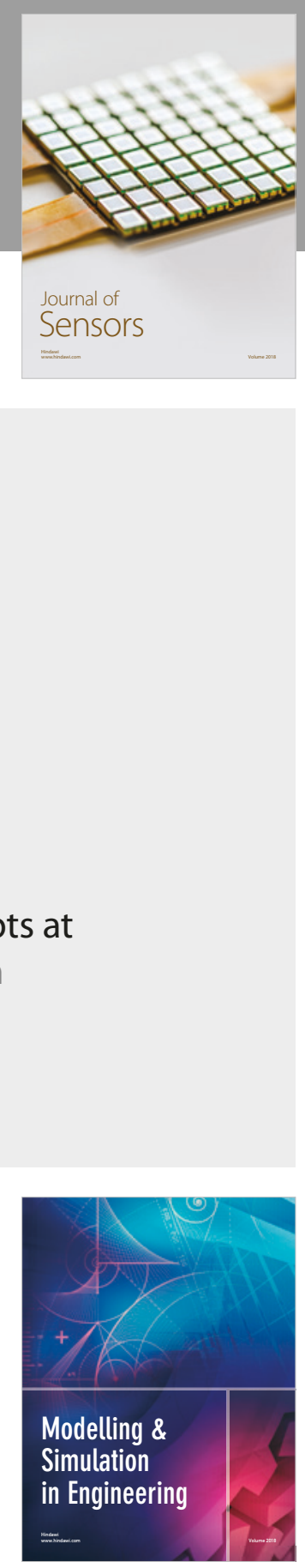

\section{Advances \\ Multimedia}
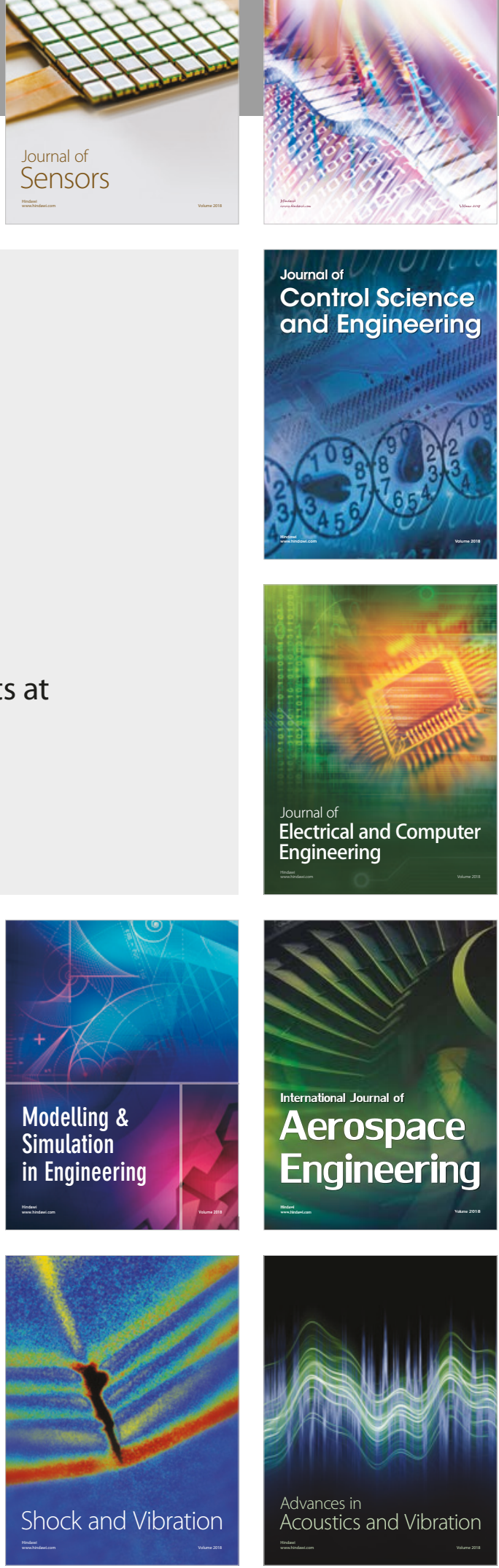